Ann. Biol. anim. Bioch. Biophys., I970, 10 (r), 73-79.

\title{
INFLUENCE DE LA NATURE DES LIPIDES ALIMENTAIRES SUR LE TRANSFERT DES CAROTÉNOÏDES A L'CEUF
}

\author{
J.-C. BLUM et B. LECLERCQ \\ avec la collaboration de Solange Guillaumin \\ Station de Recherches avicoles, \\ Centre de Recherches de Tours, 37 - Nouzilly \\ Institut national de la Recherche agronomique
}

RÉSUMÉ́

Chez la Poule pondeuse, l'utilisation des caroténoïdes de la luzerne paraît đépendre de la nature des lipides, introduits à raison de $4 \mathrm{p}$. Ioo dans un régime sans graisse. La pigmentation du vitellus augmente significativement lorsque l'aliment contient du suif. Elle n'est pas modifiée, en dépit d'un apport important de vitamine E et de BHT, lorsque les animaux ingèrent des huiles désaturées (olive, tournesol). Ces résultats sont inexplicables si l'on considère que les acides gras ont seulement un effet passif sur la solubilité et la stabilité des caroténoïdes.

\section{INTRODUCTION}

Les caroténoïdes étant des pigments liposolubles, les lipides devraient faciliter leur absorption intestinale et leur transfert au jaune de l'œuf. Dans cet espoir, divers auteurs ont ajouté des graisses à la ration de la Poule. Les résultats obtenus sont contradictoires. L'addition d'une " graisse animale ", relativement riche en acides gras saturés, n'a pas d'effet sur la pigmentation du vitellus selon SuI,IIVAN et HoL,LEman (r962), tandis que pour MACKAY, MounTEY et NABER (1963), elle augmente notablement la teneur de l'œuf en caroténoïdes. L'introduction d'une huile désaturée (tournesol, poisson) peut réduire l'utilisation des xanthophylles (Hammond et HARShaW, I94I) ; mais le plus souvent, elle n'a aucun effet sur la pigmentation du jaune d'œuf (Marusich, AcKerman et BaUternfeind, I962 ; Madiedo et Sunde, I964). SAUNDERS et al. (I967) expliquent ces observations contradictoires en considérant que l'influence des graisses est double : favorable sur l'absorption et défavo- 
rable sur la stabilité des caroténoìdes, les acides gras étant des agents d'oxydation surtout lorsqu'ils sont très désaturés. Cette thèse est appuyée par des résultats montrant que l'huile de tournesol peut augmenter la pigmentation du vitellus lorsque le régime contient des antioxydants (BH'T, vitamine E).

Toutes ces études concernent une seule graisse ajoutée le plus souvent à un régime à base de mais contenant donc déjà une assez forte proportion de lipides (riches en acides gras désaturés). Pour savoir si la nature des graisses a une influence, il fallait les introduire une à une dans un régime lipidoprive et comparer leur effet au cours d'une même expérience. C'est ce que nous avons cherché à faire en utilisant 3 matières grasses dont les compositions en acides gras sont très différentes : le suif, l'huile d'olive et 1'huile de tournesol. Pour établir une base de comparaison valable, nous avons préservé les caroténoïdes en ajoutant des antioxydants (BH'T, vitamine E).

\section{MATÉRIEL ET MÉTHODES}

\section{A. - Animaux et régimes}

L'expérience porte sur 72 poules issues d'un croisement commercial de Rhode Island Red (Hubbard Autosex) vivant en cages individuelles.

La première période, période préexpérimentale, débute après 3 mois de régime de base dépourvu de lipides et pauvre en caroténoïdes. La composition de ce régime de base figure dans le tableau $I$.

Au début de l'expérience, on constitue 8 lots comprenant chacun 8 poules choisies de manière à ce que les lots soient aussi homogènes que possible (poids des animaux, poids des œufs, intensité de ponte). On leur distribue les régimes suivants :

$$
\begin{array}{ll}
\begin{array}{c}
\text { Lot Témoin } \\
\text { (Base) }
\end{array} & \left\{\begin{array}{l}
\mathrm{B} o=\text { Régime sans lipides } \\
\mathrm{B} c=\text { Régime sans lipides }
\end{array}\right. \\
\text { Lot Suif } & \left\{\begin{array}{l}
\mathrm{S} o=\text { Régime Suif } \\
\mathrm{S} c=\text { Régime Suif }
\end{array}\right. \\
\text { Lot Olive } & \left\{\begin{array}{l}
\mathrm{O} o=\text { Régime Olive } \\
\mathrm{O} c=\text { Régime Olive }
\end{array} \quad+\text { Caroténoïdes (1o } \mathrm{mg} / \mathrm{kg}\right)
\end{array}
$$

La composition des régimes Suif, Olive et Tournesol est indiquée dans le tableau I. Elle est semblable à celle du régime de base ; une partie de l'amidon est remplacée par un mélange cellulose + graisse (suif, huile d'olive ou huile de tournesol selon le régime) introduite à raison de

\begin{tabular}{|c|c|c|c|}
\hline & $\begin{array}{l}\text { Acides gras } \\
\text { saturés }\end{array}$ & $\begin{array}{c}\text { Acide } \\
\text { oléique }\end{array}$ & $\begin{array}{c}\text { Acide } \\
\text { linoléique }\end{array}$ \\
\hline Suif & 62 & 34 & 2 \\
\hline Huile d'olive....... & 16 & 70 & 14 \\
\hline Huile de tournesol & 12 & 26 & 61 \\
\hline
\end{tabular}
4 p. Ioo. De ce fait, tous les régimes sont isoénergétiques (2 $876 \mathrm{cal}$. métabolisables $/ \mathrm{kg}$ ) et renferment les mêmes protéines ( 16 p. I00). Les graisses sont toutes de qualité supérieure : à peine colorées, elles renferment apparemment très peu de xantophylles ; leur composition en acides gras (exprimée en p. cent des acides gras totaux) permet de les caractériser : 
Les caroténoïdes de la luzerne incorporés à ces régimes sont sous forme d'une poudre commercialisée sous le nom de "xantalfa" $\left({ }^{1}\right)$.

Au cours des deux périodes (préexpérience et expérience), on contrôle l'intensité de ponte et le poids des œufs.

TABLEAU I

Composition des régimes

(en $\mathrm{kg} /$ Ioo $\mathrm{kg}$ de régime)

\begin{tabular}{|c|c|c|}
\hline & $\begin{array}{l}\text { Régime de base } \\
\text { sans lipide }\end{array}$ & $\begin{array}{c}\text { Régime Suif, Olive } \\
\text { ou Tournesol }\end{array}$ \\
\hline Tourteau d'arachide...... & 20 & 20 \\
\hline Lait écrémé en poudre.. & 15 & 15 \\
\hline Amidon $\ldots \ldots \ldots \ldots \ldots$ & 54 & 44 \\
\hline Cellulose.... . . . . . . . & 2,3 & 8,3 \\
\hline Matières grasses $\left({ }^{\mathbf{1}}\right) \ldots \ldots$ & 0 & 4 \\
\hline Phosphate bicalcique .... & 1,5 & 1,5 \\
\hline Calcimarine $\ldots \ldots \ldots$ ! & 5,5 & 5,5 \\
\hline Bicarbonate de Na...... & 0,5 & 0,5 \\
\hline Oligoéléments........ & 0,2 & 0,2 \\
\hline \multirow{2}{*}{$\begin{array}{l}\text { Mélange vitaminique }\left({ }^{2}\right) \\
\text { dont vitamine E et } \mathrm{BHT}\end{array}$} & & \\
\hline & 1 & 1 \\
\hline
\end{tabular}

(1) Suif, huile d'olive ou huile de tournesol selon le régime.

(2) Composition du mélange vitaminique : Vitamine $\mathrm{A}=800000 \mathrm{UI}$; Vitamine $\mathrm{D}_{3}=100000 \mathrm{UI}$; Ménadione $=0,050 \mathrm{~g}$; Thiamine $\mathrm{HCl}=0,4 \mathrm{~g}$; Riboflavine $=0,4 \mathrm{~g} ;$ Pantothénate de calcium $=0,7 \mathrm{~g} ;$ Niacine $=1 \mathrm{~g}$; Pyridoxine $\mathrm{HCl}=0,4 \mathrm{~g} ;$ Vitamine $\mathrm{B}_{12}=0,001 \mathrm{~g} ;$ Choline $=100 \mathrm{~g}$; DL-méthionine $=150 \mathrm{~g} ;$ Vitamine $\mathrm{E}=5 \mathrm{~g} ; \mathrm{BHT}=10 \mathrm{~g} ;$ Avoine broyée q. s. p. $1000 \mathrm{~g}$.

\section{B. - Pigmentation du jaune d'ceuf}

Elle est appréciée directement à l'aide de l'échelle " Roche " et par dosage des caroténoïdes dans le vitellus.

Pendant dix jours, à la fin de la période préexpérimentale et pendant le même laps de temps après 3 semaines d'expérience, on casse tous les oufs pour mesurer à l'aide de l'échelle "Roche " la pigmentation du vitellus. Après séparation de l'albumen, le vitellus est entreposé à $-20^{\circ}$ et à l'obscurité dans un récipient hermétique. A la fin de chaque période de ro jours, on réunit les jaunes d'œufs provenant de la même poule. Après homogénéisation, on extrait les xanthophylles par l'acétone. On les dose en utilisant la technique préconisée par Marnguy et Rougues (1965): l'extrait est saponifié et chromatographié sur colonne de magnésie ; on mesure au spectrophotomètre l'extinction dans l'alcool à $45^{\circ} \mathrm{m} \mu$.

\section{RÉSULTATS}

\section{A. - Intensité de ponte et poids de l'cuf}

L'intensité de ponte est de l'ordre de 50 à 60 p. Ioo dans tous les lots. Entre les deux périodes de mestre (Io jours avant et Io jours après 3 semaines d'expérience) le poids moyen des œufs a augmenté de 3,5 p. Ioo dans les lots Témoins contre

(1) Laboratoire Probione, o8 - Tournes (France). 
5,5 p. Ioo, 6 p. Ioo et 6,5 p. Ioo respectivement dans les lots Suif, Olive et Tournesol. Mais la différence n'est significative $(\mathrm{P}<0,02)$ qu'entre les lots Témoins $\left(\mathrm{B}_{o}+\mathrm{B}_{c}\right)$ et Tournesol ( $\mathrm{T}_{o}$ et $\mathrm{T}_{c}$ ).

\section{B. - Pigmentation du jaune d'œuf}

A la fin de la période préexpérimentale, le vitellus de l'œuf est très pâle (I dans l'échelle " Roche ") ; sa teneur en caroténoïdes est de $I, 8 \mu \mathrm{g} / \mathrm{g}$, elle varie très peu d'un animal à l'autre (écart-type $=0,10$ ). L,es résultats obtenus après 3 semaines d'expérience sont indiqués dans le tableau 2.

TABLEAU 2

Infuence des lipides sur le transfert des caroténoïdes à l'ouf

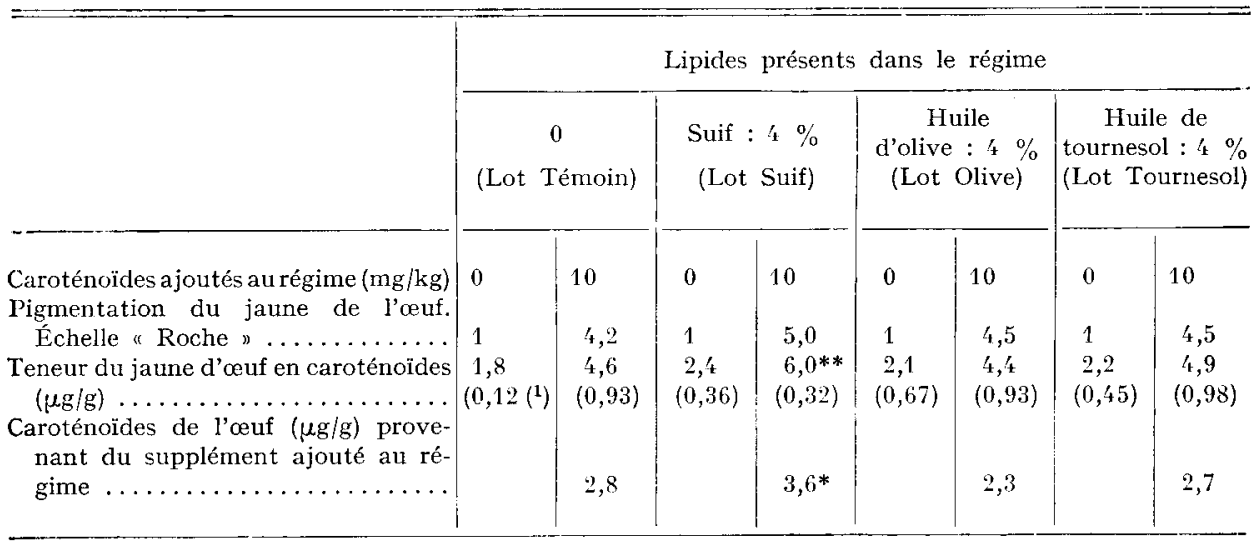

(1) Écart-type.

** Différence très significative avec le lot témoin $(\mathrm{P}<0,01)$, avec le lot Olive $(\mathrm{P}<0,01)$ et avec le lot Tournesol $(\mathrm{P}<0,02)$.

* Différence non significative avec le lot Témoin $(0,1>\mathrm{P}>0,05)$ mais significative avec le lot Olive $(P<0,01)$, le lot Tournesol $(P=0,05)$ et avec les 3 lots réunis : Témoin, Olive, Tournesol $(P=0,02)$.

L'apport alimentaire de caroténoïdes n'étant jamais très important, même après supplémentation, la pigmentation du vitellus reste modérée et se situe dans une zone de sensibilité maximum pour apprécier la richesse en caroténoïdes à l'aide de l'échelle "Roche " (Mainguy et Rouques, I965). Cette méthode de mesure demeure cependant très subjective. On peut seulement noter un accroissement de la coloration du jaune après addition de caroténoïdes au régime. Les différences entre lots sont peu accusées, le suif paraît avoir une action plus marquée que les autres graisses.

Le dosage des caroténoïdes fournit une base d'appréciation autrement précise. Dans tous les cas, la teneur de l'œuf dépend de celle du régime, mais pour un apport alimentaire identique (o ou ro $\mathrm{mg} / \mathrm{kg}$ ) on ne note aucune différence significative entre les lots Témoin, Olive et Tournesol. Cette absence d'effet des deux huiles désaturées souligne 1'influence favorable du suif sur la pigmentation du jaune d'œuf. Chez les poules ingérant des caroténoïdes ( $\mathrm{I} 0 \mathrm{mg} / \mathrm{kg}$ ) la concentration du vitellus est de $6,0 \mu \mathrm{g} / \mathrm{g}$ dans le lot Suif $\left(\mathrm{S}_{c}\right)$ contre $4,6,4,4$ et 4,9 dans les lots 'Témoin $\left(\mathrm{B}_{c}\right)$, Olive $\left(\mathrm{O}_{c}\right)$ et 
Tournesol $\left(\mathrm{T}_{e}\right)$; les différences étant toutes très significatives. Chez les animaux ne consommant pas de caroténoïdes, le suif accroît déjà légèrement la teneur du vitellus (différence significative seulement avec les témoins $B_{0}$ ). De ce fait, les écarts entre le lot Suif et les autres lots subsistent, mais sont moins accusés lorsqu'on détermine par différence l'enrichissement en caroténoïdes provenant du supplément (Io $\mathrm{mg} / \mathrm{kg}$ ) ajouté à la ration. Pour le lot Suif, cet enrichissement est de 3,6 $\mu \mathrm{g} / \mathrm{g}$ de jaune, il surpasse nettement ceux enregistrés dans les autres lots : Témoin $=2,8$, Olive $=2,3$ et Toturnesol $=2,7 \mu \mathrm{g} / \mathrm{g}$. Mais si la différence demeure significative avec les lots Olive $(P<0, O I)$, Tournesol $(P=0,05)$, Témoin-Olive-Tournesol réunis $(P=0,02)$, elle n'atteint pas tout à fait le seuil de la signification avec le seul lot Témoin.

\section{DISCUSSION}

En constatant que les poules du lot Tournesol pondent de plus gros œufs que les animaux témoins, nous ne faisons que vérifier un fait maintenant bien établi : un apport alimentaire minimum d'acide linoléique est indispensable pour que le poids de l'œuf atteigne une valeur maximum (LECLERCQ, BLUM et DELPECH, I969).

L'effet des différentes graisses sur la pigmentation du jaune d'œuf est plus surprenante. Si l'on en croit les travaux de SAUNDERs et al. (I967), les caroténoïdes devraient être protégés par le $\mathrm{BH}$ ' et la vitamine $\mathrm{E}$ et, de ce fait, utilisés au mieux lorsque le régime renferme une huile insaturée réputée particulièrement digestible (Biederman et Prabucki, I969). En contradiction flagrante avec ce point de vue, notre essai montre que les huiles insaturées n'améliorent pas le transfert des caroténoïdes au vitellus, tandis que le suif, qui est moins digestible, a une influence positive manifeste. Une oxydation due à la présence des acides gras insaturés est d'autant plus improbable que les aliments contenant des graisses sont conservés moins de 2 semaines, leur préparation étant constamment renouvelée.

Dans 1'état actuel de nos connaissances, il paraît difficile d'expliquer ces résultats. L'action directe des graisses sur la solubilité et la stabilité des xanthophylles ne constitue peut-être qu'un des aspects du problème ; on pourrait également invoquer des effets indirects. L'un d'entre eux concernerait la compétition qui s'établit pour le transfert à l'œuf entre les divers caroténoïdes et la vitamine A qui, on le sait, a une structure chimique analogue. C'est ainsi que HAYEs (I966) constate que la pigmentation du vitellus diminue significativement lorsque le régime contient plus de 53000 UI de vitamine $\mathrm{A}$ par $\mathrm{kg}$. Cet effet du rétinol disparaît complètement après addition à l'aliment de $3 \mathrm{p}$. Ioo de suif. Autrement dit, dans l'expérience de HAYEs (I966), le suif permet d'augmenter la teneur du vitellus en caroténoïdes lorsque l'apport de vitamine A est excessif. Dans le cas contraire (apport de vitamine A normal), le suif n'a aucune influence sur la coloration du jaune d'œuf. Dans notre essai, si l'aliment ne contient pas une quantité excessive de rétinol (supplémentation : 8 ooo UI $/ \mathrm{kg}$ ), il ne renferme pas non plus une dose élevée de caroténoïdes. Certains de ces derniers sont d'ailleurs si faiblement incorporés dans l'œuf que, à l'instar de la vitamine $A$, ils ne pourront que gêner l'utilisation des autres. Une telle compétition entre la vitamine $A$, le carotène et les diverses xanthophylles pourrait expliquer la faible valeur du taux de transfert des caroténoïdes de la luzerne chez les animaux témoins. Il est certain que les variations individuelles sont atténuées dans le lot Suif 
(écart-type réduit : Cf. tabl. 2) comme si un effet inhibiteur, variant suivant les individus, pouvait disparaître lorsque les poules ingèrent du Suif.

En ce qui concerne les acides gras insaturés, on peut évoquer leur rôle dans la perméabilité des membranes et leur action inhibitrice sur l'activité de nombreux enzymes (ANonyme, I969). Dans le cas des caroténoïdes et substances analogues, on sait seulement chez le Rat, que les acides gras insaturés diminuent la rétention hépatique et augmentent l'excrétion fécale de la vitamine A (IWANOwski et PAczEK, 1967).

En définitive, l'action des différentes graisses sur la coloration du jaune de læeuf paraît très complexe. Le résultat obtenu pourra dépendre de nombreux facteurs alimentaires tels que la teneur en vitamine $\mathrm{A}$, la quantité et la qualité des caroténoïdes de la ration. Dans nos conditions expérimentales (apport faible de xanthophylles provenant de la luzerne ; régime de base sans lipide), le suif a pu augmenter la pigmentation du vitellus, les huiles désaturées (olive, tournesol) n'ont eu aucun effet. Dans nos prochains essais, nous essaierons de préciser l'influence de la dose et de la qualité des caroténoïdes ingérés, qualité qui est peut-être altérée dans le cas du "Xantalfa » du fait des procédés d'extraction.

Reçu pour publication en novembre 1969.

\author{
SUMMARY \\ INFL,UENCE OF THE NATURE, OF THE LIPIDS IN THE FEED ON THE \\ TRANSFER OF CAROTENOIDS TO THE EGG
}

Tallow, olive oil or sunflower oil were included as 4 per cent in diets without other sources of fat and containing anti-oxidants : vitamin $\mathrm{E} 5 \mathrm{mg}$ and butylated hydroxytoluene roo $\mathrm{mg}$ per $\mathrm{kg}$. Small amounts of carotenoids extracted from lucerne, Io $\mathrm{mg}$ per $\mathrm{kg}$, were added to the diets. A total of 8 groups of 8 hens were distributed according to the diets : without or with the fats, tallow, olive oil or sunflower oil, each without or with the carotenoids.

In hens given olive oil or sunflower oil the xanthophyll content of the egg yolk was of the same order as for controls on the diet without fat. Of the 3 fats studied only tallow had a positive effect on pigmentation of the yolk. In hens which got carotenoids the content in yolk was $6.0 \mu \mathrm{g}$ against $4.6 \mu \mathrm{g}$ in the controls ; the difference was highly significant. These results seem inexplicable if one considers that the fatty acids have only a passive effect on the solubility and stability of the xanthophylls in the diet. Other factors, such as the quantity and quality of the carotenoidsingested must be taken into consideration.

\title{
RÉFÉRENCES BIBLIOGRAPHIQUES
}

Anonyme, I969. Inhibitory effects of free fatty acids on enzyme activity : specific or non-specific? Nutr. Rev., 27, $125-127$.

Biedermann R., Prabucki A. L., r969. Über den Einfluss von Art und Menge des Futterfettes auf die Einslagerung von Carotinoiden in das Hühnerei. Arch. Gefliigelfk., 33, 103-I 8.

Hammond J. C., Harshaw H. M., I94I. Some factors influencing shank and skin color in the growing chicken. Poult. Sci., 20, 437-444.

HAYES J. P., I966. Influence of high levels of vitamin A in combination with beef tallow on egg yolk colour. S. Afr. J. Agric. Sci., 9, $46 \mathrm{r}-466$.

Iwanowski S., PACzeK K., 1967. The influence of some unsaturated fatty acids on vitamin A. Acta Physiol. Polon., 18, 963-972. 
I.eclercQ B., BLum J.-C., Delpech P., 1969. Influence du régime maternel sur la croissance du jeune poussin. Effets d'une déficience en acide linoléique. Ann. Biol. anim. Bioch. Biophys., 9, I9r-204.

Mackay E., Moutney G. J., Naber E. C., I963. Yolk color resulting from different levels of paprika extract in the ration. Poult. Sci., 42, 32-37.

Madiedo G., Sunde M. L., r964. The effect of algae, dried lake weed, alfalfa and ethoxyquin on yolk color. Poult. Sci., 43, 1056-1061.

Mainguy P., Rougues A., I965. Le jaune de l'œuf. I. Étude générale de la couleur. II. la couleur des oufs du marché français. Bull. Soc. Sci. Hyg. Alim., 53, 83-116, 194-212.

Marusich W. L., Ackerman G. L., Bauernfeind J. C., I962. Effect of feed additives on yolk pigmentation. Poult. Sci., 41, I664.

Saunders C. F., Hayes J. P., Erasmus J., Jooste J. P., Duplessis P. H. C., Venter E. L., I967. Egg yolk pigmentation as influenced by BHT, vitamine $\mathrm{E}$ and sunflower oil. S. Afr. J. Agric. Sci. $10,373-385$.

Sullivan T. W., Holleman K. A., r962. Effect of alfalfa meal, corn gluten meal and other dietary components on egg yolk color. Poult. Sci., 41, I474-1478. 